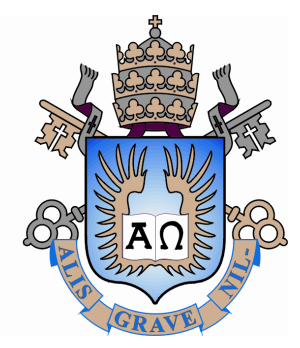

Christiane Aguiar de Andrade

Uma análise da influência dos incentivos fiscais na localização de centros de distribuição

\begin{abstract}
Dissertação de Mestrado
Dissertação apresentada como requisito parcial para obtenção do título de Mestre em Logística (opção profissional) pelo Programa de PósGraduação em Engenharia Industrial da PUC-Rio.

Orientador: Ph.D. Nélio Domingues Pizzolato
\end{abstract}

Rio de Janeiro

Agosto de 2008 


\section{Uma análise da influência dos incentivos fiscais na localização de centros de distribuição}

Dissertação apresentada como requisito parcial para obtenção do título de Mestre em Logística (opção profissional) pelo Programa de Pós-Graduação em Engenharia Industrial da PUC-Rio. Aprovada pela Comissão Examinadora abaixo assinada.

Ph.D. Nélio Domingues Pizzolato Orientador Departamento de Engenharia Industrial - PUC - Rio

D.Sc. Luiz Felipe Roris Rodriguez Scavarda do Carmo Departamento de Engenharia Industrial - PUC - Rio

D.Sc. Madiagne Diallo Departamento de Engenharia Industrial - PUC - Rio

Dr. Ing. José Eugênio Leal Coordenador Setorial do Centro Técnico Científico - PUC-Rio

Rio de Janeiro, 27 de agosto de 2008. 
Todos os direitos reservados. É proibida a reprodução total ou parcial do trabalho sem autorização da universidade, da autora e do orientador.

Christiane Aguiar de Andrade

Administradora de Empresas graduada pela UFRRJ, atua há mais de 10 anos na área de Logística em empresa multinacional e é professora da UFRRJ, onde ministra aulas de Logística e Gestão de Sistemas de Informação para o Bacharelado em Administração de Empresas.

Ficha Catalográfica

Andrade, Christiane Aguiar de

Uma análise da influência dos incentivos fiscais na localização de centros de distribuição / Christiane Aguiar de Andrade ; orientador: Nélio Domingues Pizzolato. -2008.

104 f. : il. (color.) ; $30 \mathrm{~cm}$

Dissertação (Mestrado em Engenharia Industrial)-Pontifícia Universidade Católica do Rio de Janeiro, Rio de Janeiro, 2008.

Inclui bibliografia

1. Engenharia industrial - Teses. 2. Centros de distribuição. 3. Incentivos fiscais. 4. Localização. I. Nélio Domingues Pizzolato. II. Pontifícia Universidade Católica do Rio de Janeiro. Departamento de Engenharia Industrial. III. Título.

CDD: 658.5 
A felicidade não se consegue pela via da liberdade sem a verdade, porque esta é a via do egoísmo irresponsável, que divide e corrói a família e a sociedade. 


\section{Agradecimentos}

Sabe tese, de faculdade? Aquela que defendem? Com unhas e dentes? É dessa tese que eu estou falando. Você deve conhecer pelo menos uma pessoa que já defendeu uma tese...

Escrever uma tese é quase um voto de pobreza que a pessoa se autodecreta. $\mathrm{O}$ mundo pára, o dinheiro entra apertado, os filhos são abandonados, o marido que se vire. Estou acabando a tese. Essa frase significa que a pessoa vai sair do mundo.

E, depois de terminada a tese, tem a revisão da tese, depois tem a defesa da tese. E, depois da defesa, tem a publicação. E, é claro, intelectual que se preze, logo em seguida embarca noutra tese.

Têm viagens, compra de livros caros, horas na Internet da vida, separações, pensão para os filhos que a mulher levou embora. É, defender uma tese é mesmo um voto de pobreza, já diria São Francisco de Assis...

Não pode comprar bicicleta por causa da tese. A gente não pode ir para a praia por causa da tese. Tudo é pra quando acabar a tese. Até trocar o pano do sofá...

(Mário Prata)

Primeiramente, agradeço a Deus, criador de todas as coisas visíveis e invisíveis, por todos os mimos e pelas incontáveis conquistas. Que o meu coração jamais se esvazie dessa gratidão, ou nada terá valido à pena;

Ao meu esposo, Wagner, acima de tudo pelo seu amor incondicional. E ainda pelas contribuições efetivas: críticas, sugestões e pelo seu senso prático, que diversas vezes me fez perceber que algo poderia ser muito mais simples do que eu imaginava. Em alguns momentos, eu não saberia como continuar, se não pelo 
seu incentivo: "Você sabe que é capaz. Não se desespere! Em se acabando a esperança, acaba-se também a vida!";

Ao meu filho, Miguel, por ter-se comportado direitinho nos inúmeros finais de semana em que a mamãe precisou ficar longe do seu sorriso, do azul dos seus olhos e das suas travessuras. Sem dúvida, essa foi a parte mais difícil... Que um dia tudo isso lhe sirva de exemplo e inspiração;

Ao meu pai, José, de quem eu herdei o gosto pelos estudos, a curiosidade diante de qualquer oportunidade de aprender e a vocação para o trabalho, presente na alma de qualquer português, ainda que nascido em outro país, como eu!

À minha mãe, Gloria, pela sua personalidade forte, imbatível diante das adversidades da vida, e pelo seu temperamento doce e sensato, o qual eu tento imitar todos os dias. E ainda pelas comidinhas deliciosas dos finais de semana em que estive 'exilada' em sua casa, desfrutando da paz e do silêncio necessários à produção desse texto;

Aos meus tios, Carlos e Alice, que são como meus segundo pais, e ao meu primo Dhouglas, pela admiração, pelo reconhecimento e por terem cuidado do Miguel algumas vezes, sobretudo no dia da defesa;

Aos meus sogros, Valter e Josefa, e à minha cunhada, Kelly, pelo afeto e pelas boas gargalhadas, que foram essenciais para relaxar e esquecer um pouco a tensão;

A Dom Dimas Lara Barbosa, Secretário Geral da Conferência Nacional dos Bispos do Brasil (CNBB), cujo amor fraterno viabilizou esse projeto;

Ao meu orientador, Nélio Pizzolato, pela amizade e total compreensão nos momentos difíceis. Pelas suas palavras de otimismo (“A vida de um pesquisador começa após a defesa; Seu trabalho está bom! Siga confiante...");

E a todos que, direta ou indiretamente, ajudaram, criticaram, rezaram... 


\section{Resumo}

Andrade, Christiane Aguiar de. Uma análise da influência dos incentivos fiscais na localização de centros de distribuição. Rio de Janeiro, 2008. 104p. Dissertação de Mestrado - Departamento de Engenharia Industrial, Pontifícia Universidade Católica do Rio de Janeiro.

Atualmente, uma das estratégias adotadas pelas empresas para reduzir seus custos e se manterem competitivas passa pela Logística Tributária, que vislumbra as oportunidades de redução de impostos na Logística por meio de incentivos fiscais ou financeiros. Como conseqüência do avanço tecnológico, os produtos são cada vez mais equivalentes, no que diz respeito à sua qualidade e funcionalidade e, de uma forma geral, as boas práticas são absorvidas muito rapidamente pelo mercado, restando às organizações a redução da margem de lucro e a minimização dos custos, mais especificamente, do custo logístico. A maioria dos incentivos fiscais e financeiros oferecidos no Brasil se concentra longe dos principais centros consumidores, tornando-se necessário associar o planejamento tributário aos métodos de localização e considerar os trade-offs entre benefícios e custos operacionais. Analisar a infra-estrutura oferecida pelo Estado é outra forma de evitar perdas no nível de serviço logístico, que podem gerar conseqüências imensuráveis em curto prazo. O presente trabalho é uma análise da influência dos incentivos fiscais sobre a decisão de localização de centros de distribuição e pressupõe o caso de uma empresa fictícia que se instalou no Estado do Espírito Santo, com o objetivo de se beneficiar do Fundap, um incentivo às importações, oferecido por aquele estado.

\section{Palavras-chave}

Centros de distribuição; Incentivos Fiscais; Localização 


\section{Abstract}

Andrade, Christiane Aguiar de. Analysis of the tax incentives impact in distribution centers localization. Rio de Janeiro, 2008. 104p. Dissertação de Mestrado - Departamento de Engenharia Industrial, Pontifícia Universidade Católica do Rio de Janeiro.

In the present days, one of the strategies adopted by companies to reduce their costs and hold their competitiveness involves the tributary logistics, which considers the opportunities of taking into account the taxes advantages derived from locating distribution centers in certain areas or states that offer financial incentives. As a consequence of the technology improvement, products tend to be even more equivalents regarding their quality and functionality. In a general way, good practices are very rapidly absorbed by the market, so that the organizations have to face the reduction of the profit margin and the minimization of costs, in particular the logistics costs. The majority of taxes and financial incentives offered in Brazil is concentrated away from the main consumer centers, becoming necessary to associate the tax planning with the location methods, in order to consider the trade-offs between benefits and the operational costs. Analyzing the public infrastructure offered by the government is another way to avoid the losses at the level of logistics services. It may generate immeasurable consequences in the short term. The present work is an analysis of the influence of the tax incentives in the decision of locating distribution centers and assumes the case of a hypothetical company that was installed in the state of Espírito Santo, in order to take advantage of benefits granted by Fundap, the local state agency that offers incentive for imported goods.

\section{Key-word}

Distribution Centers; Tax Incentives; Localization 


\section{Sumário}

1 Introdução 11

1.1 Objetivos 12

1.2 Delimitação do escopo da dissertação 14

$\begin{array}{lll}1.3 & \text { Metodologia científica } & 15\end{array}$

$\begin{array}{lll}1.4 & \text { Estrutura da dissertação } & 15\end{array}$

2 Sistema Tributário $\quad 17$

$\begin{array}{ll}2.1 & \text { Um pouco de história }\end{array}$

2.2 O Sistema Tributário brasileiro 19

2.2.1 Espécies de tributos 21

2.2.2 Alguns princípios aplicáveis aos tributos 26

$\begin{array}{ll}2.3 \text { O cenário atual } & 27\end{array}$

2.4 A tão falada (e esperada) Reforma Tributária 31

2.5 O ICMS: Imposto sobre circulação de mercadorias e serviços 34

2.5.1 Alguns princípios aplicáveis ao ICMS 39

3 Incentivos Fiscais e Financeiros $\quad 40$

3.1 Elisão e evasão fiscal 42

3.2 A guerra fiscal 44

3.3 Exemplos de incentivos relevantes à decisão de localização de $\begin{array}{ll}\text { centros de distribuição } & 46\end{array}$

3.3.1 Zona Franca de Manaus 46

3.3.2 FUNDAP (Estado do Espírito Santo) 50

4 A Logística 54

4.1 Introdução 54

4.2 As principais atividades de um centro de distribuição 63

4.3 O custo logístico 64

4.3.1 Custo de armazenagem e movimentação 66 
4.3.2 Custo de embalagem 68

4.3.3 Custo de transporte $\quad 69$

$\begin{array}{lll}\text { 4.3.4 Custo de oportunidade } & 72\end{array}$

4.4 A Logística Tributária 72

4.5 Localização de instalações $\quad 75$

$\begin{array}{lll}\text { 4.5.1 } & \text { Principais métodos de localização } & 77\end{array}$

5 Estudo de Caso 83

5.1 A empresa 83

5.2 A demanda $\quad 84$

5.3 A distribuição $\quad 84$

5.4 O planejamento tributário: importações a partir do Espírito Santo, com o benefício do FUNDAP 85

5.5 A estrutura de custos a partir da adesão ao Fundap 87

6 Conclusão 92

7 Referências bibliográficas 96 